\title{
Soil Moisture Memory in Climate Models
}

\author{
Randal D. Koster ${ }^{1}$ and Max J. Suarez ${ }^{2}$
}

${ }^{1}$ Hydrological Sciences Branch, Laboratory for Hydrospheric Processes, NASA/Goddard Space Flight Center, Greenbelt, MD USA

${ }^{2}$ Climate and Radiation Branch, Laboratory for Atmospheres, NASA/Goddard Space Flight Center, Greenbelt, MD USA

November 3, 2000

Submitted to Journal of Hydrometeorology 


\begin{abstract}
Water balance considerations at the soil surface lead to an equation that relates the autocorrelation of soil moisture in climate models to (1) seasonality in the statistics of the atmospheric forcing, (2) the variation of evaporation with soil moisture, (3) the variation of runoff with soil moisture, and (4) persistence in the atmospheric forcing, as perhaps induced by landatmosphere feedback. Geographical variations in the relative strengths of these factors, which can be established through analysis of model diagnostics and which can be validated to a certain extent against observations, lead to geographical variations in simulated soil moisture memory and thus, in effect, to geographical variations in seasonal precipitation predictability associated with soil moisture. The use of the equation to characterize controls on soil moisture memory is demonstrated with data from the modeling system of the NASA Seasonal-to-Interannual Prediction Project.
\end{abstract}




\section{Introduction}

A period of atypically heavy rainfall can produce a positive anomaly in soil moisture, and the dissipation of that anomaly through evaporation and other processes may take weeks to months. Similar timescales apply to the dissipation of negative soil moisture anomalies (atypically dry soil). In effect, the soil can "remember" the wet or dry conditions that caused an anomaly long after these conditions have been forgotten by the atmosphere.

Quantifying soil moisture persistence - soil moisture "memory" - requires long-term (multi-decadal) records of soil moisture, and unfortunately such records do not exist in many parts of the world. Some areas, chiefly in Asia, do have substantial data, however [Robock et al., 2000]. Vinnikov and Yeserkepova [1991] analyzed Russian soil moisture and derived anomaly decay timescales of two or three months for several monitoring sites. Vinnikov et al. [1996] found a similar timescale when analyzing data from the Valdai station in Russia, and Entin et al. [2000] derived timescales of about two months from Chinese, Mongolian, and Illinois data. Useful alternatives to direct soil moisture measurements include model-generated soil moistures, particularly when the models are driven by observed meteorological conditions. Huang et al. [1996], for example, inferred soil moisture data from precipitation and temperature measurements and showed that soil moistures in the United States are significantly correlated with surface temperatures observed several months later, a strong indication that soil moisture memory 
is important at those lags. Georgakakos et al. [1995] used a hydrological model to transform precipitation and pan evaporation measurements in two basins into time series of soil moisture contents that also suggest timescales of one to two months.

Such memory has profound implications for long-term weather prediction. Seasonal prediction of meteorological conditions cannot rely on the initialization and modeling of the atmosphere alone, since the timescales over which atmospheric anomalies dissipate are much too short. Seasonal forecasting must instead rely on the atmosphere's response to those components of the earth system that can be predicted months in advance, namely, the oceans and the land surface. Although the ocean has the longer memory of the two, various studies [e.g., Kumar and Hoerling, 1995; Trenberth et al., 1998; Shukla, 1998] suggest that ocean conditions have only a limited impact on predictability over most midlatitude continental regions. Thus, the memory associated with land surface soil moisture may turn out to be the chief source of midlatitude forecast skill, particularly if the atmosphere there responds in realistic and predictable ways to the soil moisture anomalies [Koster et al., 2000].

To take advantage of an observations-based specification of initial soil moisture conditions in a seasonal forecast system, the system must reproduce accurately the anomaly dissipation timescales. An understanding of what controls these timescales is thus vital. Not only is it important to get the 
right timescale for the right reason, but validation data are not available in many parts of the world, and the data that are available indicate that the timescale does vary spatially. In lieu of validating a simulated timescale directly with observations, it may be necessary to validate the simulation of the physical processes that are known to control it.

In a landmark study, Delworth and Manabe [1988] examined the physics behind soil moisture memory by modeling soil moisture variability in the Geophysical Fluid Dynamics Laboratory's atmospheric general circulation model (AGCM) as a first-order Markov process driven by random precipitation (and snowmelt) forcing, $P$ :

$$
\frac{d w(t)}{d t}=-\frac{E_{p}}{C_{s}} w(t)+P-Q
$$

where $w$ is the moisture stored in the GFDL AGCM's bucket model [Manabe, 1969], $C_{s}$ is the bucket model's water holding capacity, $E_{p}$ is the potential evaporation rate, and $Q$ is the runoff. For cases of low $Q,(1)$ relates the soil moisture anomaly timescale to the term $C_{s} / E_{p}$. The Markovian framework, which is also utilized by Huang et al. [1996], has been applied extensively to the interpretation of observational data [e.g., Vinnikov and Yeserkopova, 1991; Entin et al., 2000].

The Markovian framework, however, has at least two important limitations. First, the meteorological forcing (precipitation and radiation) is assumed to be stationary; seasonal variations in the statistics of the forcing are ignored. As will be seen, in some situations these seasonal variations have a 
critical impact on soil moisture memory. Second, persistence in the meteorological forcing is ignored. This persistence could be induced by persistence in external boundary conditions (e.g., sea surface temperatures), or it could be generated through land-atmosphere feedback. Wet soil induced by heavy rains, for example, could produce higher evaporation, which in turn could induce additional precipitation through both local recycling and modifications in the large-scale circulation. This would help to maintain the original soil moisture anomaly.

The potential impact of land-atmosphere feedback has been demonstrated in a number of studies. Rodrigues-Iturbe et al. [1991] used a statisticaldynamical model to show that this fecdback can result in multiple equilibria for soil moisture state. Koster and Suarez [1996a] examined "perpetual summer" AGCM simulations with prescribed timescales of soil moisture retention and thereby isolated a significant impact of feedback on persistence. In a series of papers, Liu and Avissar [1999ab] analyzed persistence with an AGCM coupled to a biosphere model and, with the help of an associated fourth-order analytical model, they determined that feedback with the atmosphere largely controls the seasonal timescale of simulated soil moisture anomalies.

Thus, given the possibility of either persistence in forcing (c.g., via landatmosphere feedback) or nonstationarity in forcing, a strictly Markovian framework may be inadequate for a full analysis of soil moisture memory. In the present paper, we propose a more complete framework. In section 2, 
we derive a comprehensive equation for soil moisture autocorrelation from the standard surface water balance equation. In section 3 , we test the equation globally with multi-decade AGCM results. The equation is taken apart in section 4 to show how several different physical controls combine to determine a region's soil moisture memory.

\section{Soil Moisture Autocorrelation Equation}

In the absence of snow, the water balance for the soil column of a typical land surface model (LSM), for time period (e.g., month) $n$ of year $i$, can be written:

$$
C_{s} w_{\mathrm{n}+1, \mathrm{i}}=C_{s} w_{\mathrm{ni}}+P_{\mathrm{ni}}-E_{\mathrm{ni}}-Q_{\mathrm{ni}}
$$

Here, $C_{s}$ is the column's water holding capacity, $w$ is the average degree of saturation in the column as a whole, $P$ is precipitation, $E$ is evaporation (which includes transpiration, bare soil evaporation, and interception loss), and $Q$ is runoff (which includes both overland flow and drainage out of the column). When applied to $w$, the subscript $n$ refers to the value at the beginning of the time period, and when applied to $P, E$, and $Q$, it refers to the accumulated flux over the time period.

The evaporation and runoff fluxes in an LSM are typically complex functions of numerous state variables and model parameters. Nevertheless, Koster and Milly [1997], in an analysis of results generated by many different LSMs

for the Project for the Intercomparison of Landsurface Parameterization 
Schemes (PILPS), showed that, to a large degree, the net outcome of all this complexity can be empirically approximated by simple linear functions of soil moisture. We employ this type of representation in the present statistical analysis. Here, we take:

$$
\frac{Q_{\mathrm{ni}}}{P_{\mathrm{ni}}}=a w_{\mathrm{ni}}+b
$$

and

$$
\frac{E_{\mathrm{ni}}}{R_{\mathrm{ni}}}=c w_{\mathrm{ni}}+d,
$$

where $R_{\mathrm{ni}}$ is the net radiation for the time period and where $a, b, c$, and $d$ are empirical parameters established through the analysis of lengthy LSM simulations. The adequacy of this approximation is demonstrated with AGCM results in Section 3.2.

Note that (4) is distinct from the bucket model's evaporation equation [Manabe, 1969], which underlies Delworth and Manabe's [1988] Markovian analysis of soil moisture memory. Although the two equations look similar, they are fundamentally different - evaporation in the bucket model is scaled by the potential evaporation rather than by the net radiation, and potential evaporation is strongly (negatively) correlated with soil moisture. Implications of this difference for analysis of bucket model results will be discussed in section 5 .

Substituting (3) and (4) into (2) yields, upon rearrangement,

$$
C_{s} w_{\mathrm{n}+1, \mathrm{i}}=\left(C_{s}-c R_{\mathrm{ni}}-a P_{\mathrm{ni}}\right) w_{\mathrm{ni}}+\left(P_{\mathrm{ni}}-d R_{\mathrm{ni}}-b P_{\mathrm{ni}}\right)
$$


Now consider separating the soil moisture, precipitation, and net radiation in this equation into their mean components for the given time of year (indicated by overlines) and the corresponding interannual anomalies (indicated by primes):

$$
\begin{aligned}
& w_{\mathrm{ni}}=\bar{w}_{\mathrm{n}}+w_{\mathrm{ni}}^{\prime}, \\
& P_{\mathrm{ni}}=\bar{P}_{\mathrm{n}}+P_{\mathrm{ni}}^{\prime},
\end{aligned}
$$

and

$$
R_{\mathrm{ni}}=\bar{R}_{\mathrm{n}}+R_{\mathrm{ni}}^{\prime} .
$$

Eqs. (6) - (8) can be substituted into (5) to produce a lengthy equation in terms of means and anomalies. This equation, when its time mean is subtracted from it and when higher order terms are ignored, yields the following equation for the anomalies alone:

$$
w_{\mathrm{n}+1, \mathrm{i}}^{\prime}=A_{n} w_{\mathrm{ni}}^{\prime}+B_{n} P_{\mathrm{ni}}^{\prime}-H_{n} R_{\mathrm{ni}}^{\prime},
$$

where

$$
\begin{gathered}
A_{n}=1-\frac{a \bar{P}_{\mathrm{n}}}{C_{s}}-\frac{c \bar{R}_{\mathrm{n}}}{C_{s}}, \\
B_{n}=\frac{1}{C_{s}}\left(1-a \bar{w}_{\mathrm{n}}-b\right),
\end{gathered}
$$

and

$$
H_{n}=\frac{1}{C_{s}}\left(c \bar{w}_{\mathrm{n}}+d\right) .
$$

The appearance of (9) is simplified further by combining the two forcing terms into one. Taking

$$
F_{\mathrm{ni}}^{\prime}=B_{n} P_{\mathrm{ni}}^{\prime}-H_{n} R_{\mathrm{ni}}^{\prime}
$$


we get an equation that relates the new value of $w$ to the old value and some random forcing:

$$
w_{\mathrm{n}+1, \mathrm{i}}^{\prime}=A_{n} w_{\mathrm{ni}}^{\prime}+F_{\mathrm{ni}}^{\prime}
$$

Eq. (14) serves as the basis for the derivation of the autocorrelation equation. Both sides of the equation are multiplied (in turn) by $w_{n, i}^{\prime}, w_{n+1, i}^{\prime}$, and $F_{\mathrm{ni}}^{\prime}$. Taking time means of the resulting three equations gives:

$$
\begin{gathered}
\operatorname{cov}\left(w_{\mathrm{n}}, w_{\mathrm{n}+1}\right)=A_{n} \sigma_{w_{n}}^{2}+\operatorname{cov}\left(w_{\mathrm{n}}, F_{\mathrm{n}}\right), \\
\sigma_{w_{\mathrm{n}+1}}^{2}=A_{n} \operatorname{cov}\left(w_{\mathrm{n}}, w_{\mathrm{n}+1}\right)+\operatorname{cov}\left(w_{\mathrm{n}+1}, F_{\mathrm{n}}\right),
\end{gathered}
$$

and

$$
\operatorname{cov}\left(w_{\mathrm{n}+1}, F_{\mathrm{n}}\right)=A_{n} \operatorname{cov}\left(w_{\mathrm{n}}, F_{\mathrm{n}}\right)+\sigma_{F_{\mathrm{n}}}^{2},
$$

where $\sigma_{X}^{2}$ refers to the variance of variable $X$ and where $\operatorname{cov}(X, Y)$ refers to the covariance between variables $X$ and $Y$. Note that $\sigma_{w_{\mathrm{n}}}^{2}$ and $\sigma_{w_{\mathrm{n}+1}}^{2}$ are distinct here due to an assumed seasonality of the precipitation and net radiation forcing; as discussed above, this assumption of nonstationarity is a key difference between the present analysis and the Markovian analysis of Delworth and Manabe [1988].

Equations (15)-(17) are now combined to produce an equation for the autocorrelation, $\rho$, of soil moisture:

$$
\rho=\frac{\operatorname{cov}\left(w_{\mathrm{n}}, w_{\mathrm{n}+1}\right)}{\sigma_{w_{n}} \sigma_{w_{\mathrm{n}+1}}}=\frac{A_{n} \sigma_{w_{n}}^{2}+\operatorname{cov}\left(w_{n}, F_{n}\right)}{\sigma_{w_{n}} \sqrt{A_{n}^{2} \sigma_{w_{n}}^{2}+2 A_{n} \operatorname{cov}\left(w_{n}, F_{n}\right)+\sigma_{F_{\mathrm{n}}}^{2}}} .
$$


Note that this equation relates $\rho$ to the variance of $w$ at the beginning of the time period $\left(\sigma_{w_{n}}^{2}\right)$, to the forcing and its covariance with the initial $w$ during the time period, and to the overall structure of the land surface model (through the coefficients $a, b, c$, and $d$, which underlie $A_{n}$ and $F_{n}$ ). The equation looks complex but can be simplified greatly by letting it also depend explicitly on the variance of soil moisture at the end of the time period. Squaring both sides of (14) and then taking the time mean of each side gives

$$
\sigma_{w_{n+1}}^{2}=A_{n}^{2} \sigma_{w_{n}}^{2}+2 A_{n} \operatorname{cov}\left(w_{n}, F_{n}\right)+\sigma_{F_{n}}^{2} .
$$

Substituting (19) into (18) gives, after a little manipulation, the alternative, simpler equation for $\rho$ :

$$
\rho=\frac{\sigma_{w_{\mathrm{n}}}}{\sigma_{w_{\mathrm{n}+1}}}\left[A_{n}+\frac{\operatorname{cov}\left(w_{\mathrm{n}}, F_{\mathrm{n}}\right)}{\sigma_{w_{n}}^{2}}\right]
$$

\section{Demonstration with AGCM Data}

\subsection{Model and Simulation Description}

Diagnostics generated with the NSIPP-1 AGCM of the NASA Goddard Space Flight Center provide a test of (18). This AGCM is an improved version of the model we have used in previous studies [e.g., Koster and Suarez, 1996a; Koster et al., 2000] and is currently a key component of the climate system model used by the NASA Seasonal-to-Interannual Prediction Project (NSIPP). The climatology of the NSIPP-1 AGCM is described by Bacmeister et al. [2000]. 
The land surface model (LSM) used with the AGCM is the Mosaic LSM of Koster and Suarez [1992, 1996b], a "SVAT" (soil-vegetation-atmosphere transfer) scheme that separates each grid cell into subgrid "tiles" based on vegetation class and then performs separate energy and water balance calculations over each tile. All tile quantities (evaporation, radiation, etc.) are aggregated to grid cell totals prior to performing the analyses below.

The global distribution of total water holding capacity used in the present analysis is illustrated in Figure 1. Each tile within a grid cell maintains three soil layers, with thicknesses assigned according to vegetation type. The effective grid-cell capacities in this figure, $C_{s}$, are computed from the component tile values, $C_{i}$, using

$$
\frac{1}{C_{s}}=\Sigma_{\mathrm{i}=1}^{N} \frac{f_{i}}{C_{i}},
$$

where $N$ is the number of tiles in the grid cell and $f_{i}$ is the fractional area coverage of tile $i$.

The data used for the present analysis come from an ensemble of four AGCM simulations run at $2^{\circ}$ latitude $\times 2.5^{\circ}$ longitude resolution and forced with observed sea surface temperatures. Two of the simulations span a period from the early 1950s to present, and the other two cover the period from 1980 to present. From these four simulations we extracted 129 years of data for analysis. In the following, we focus on results for July only; results for neighboring months are similar. 


\subsection{Estimated Evaporation and Runoff Functions}

The autocorrelation equation, (18), relies in part on empirically-derived linear relationships between root zone soil moisture $(w)$ and both evaporation and runoff. The actual relationships implicit in the AGCM are shown in Figure 2 for a random sampling of grid cells from the wet tropics and from a range of climates in the United States. On a given plot, the abscissa represents the degree of saturation in the root zone and the ordinate represents either the evaporation ratio $\left(\frac{E}{R}\right)$ or the runoff ratio $\left(\frac{Q}{P}\right)$, as calculated from monthly $E$, $R, Q$, and $P$ totals. Each point in the plot represents data from one of the 129 Julys simulated. Overlain on each plot is the "best fit" line from linear regression.

The plots for these representative points suggest that the assumption of linearity between $w$ and both $\frac{E}{R}$ and $\frac{Q}{P}$ is reasonable, though far from perfect. Scatter around the fitted line is small for the tropical grid cell (except at very low $w$ ) and for the eastern U.S. cell. In the eastern U.S., July evaporation is in fact insensitive to $w$ over the range of soil moistures attained. In the central U.S., scatter is significantly higher, though underlying linear relationships are still apparent, to first order.

The linearity assumption is poor in the western U.S. grid cell. In this arid cell, the vegetation fraction is small, so that evaporation is dominated by a thin surface soil layer and not by root zone moisture dynamics. Also, $Q / P$ is upwardly biased during months of little or no precipitation, during which 
drainage of the preceding month's water can still occur. (Presumably this also explains the three high points at low $w$ seen in the $\frac{Q}{P}$ plot for the central U.S.) As will be seen below, the breakdown of the linearity assumption in arid cells, though problematic, does not induce large errors in the estimation of soil moisture autocorrelation.

\subsection{Simulated Versus Predicted Autocorrelations}

Our analysis focuses on the 30-day-lagged autocorrelations $\left(\rho_{30}\right)$ of soil moisture for July, i.e., the correlation between the degree of saturation in the root zone on July 1 with that on July 31 . The global $\rho_{30}$ distribution simulated by the AGCM is displayed in Figure 3a. High values are seen in the deserts and in parts of the wet tropics, though for different reasons (Section 4). A mix of moderate and low values are seen elsewhere.

In addition to the simulated value of $\rho_{30}$ at each grid cell, we can compute an estimated value using (18). The global field of estimated $\rho_{30}$ is shown in Figure $3 \mathrm{~b}$. In this plot, a handful of negative $\rho_{30}$ values are set to zero; under some circumstances, the linearizations behind the equation allow it to "overshoot" a reduction in memory, especially at monthly and longer timescales, and accordingly, the best interpretation of a negative value from (18) is a zero value. In addition, the autocorrelations at ice-covered points, for which our analysis does not apply, are arbitrarily set to zero.

The agreement between the two maps, though not perfect, is very high 
- (18) clearly captures much of the simulated geographical variation in soil moisture autocorrelation. The scatter plot in Figure 4, showing estimated versus simulated autocorrelations, quantifies the agreement further. Each point in the plot corresponds to a single AGCM grid cell. The cloud of points is centered on the 1:1 line, and the $r^{2}$ value of 0.57 shows that (18) explains a large fraction of the geographical variation in simulated $\rho_{30}$. The standard error of estimation is 0.20 .

A significant part of the scatter in Figure 4 is related to points with little vegetation, presumably for two reasons: (i) as suggested in Figure 2, assumed linear relationships between soil moisture and both the runoff ratio and the evaporation ratio are less valid in arid regions, and (ii) these points have a much smaller water holding capacity, so that nonlinearities over the course of a month have a larger effect. When points for which the field capacity is less than $200 \mathrm{~mm}$ are removed from the analysis (Figure 5), the agreement between the simulated and estimated $\rho_{30}$ values improves, with $r^{2}$ increasing to 0.65 and the standard error of estimation decreasing to 0.16 .

\section{Interpretation of Autocorrelation Equation}

The agreement in Figure 3 implies that an understanding of the structure of (20) should lead to an understanding of why soil moisture memory is high in some regions and low in others. In other words, a study of (20) should elucidate the physical controls on memory and help us quantify their relative 
importance. Note that the expansion of the term $A_{n}$ in (20) using (10) yields the equivalent equation

$$
\rho=\frac{\sigma_{w_{\mathrm{n}}}}{\sigma_{w_{\mathrm{n}+1}}}\left[1-\frac{c \bar{R}_{\mathrm{n}}}{C_{s}}-\frac{a \bar{P}_{\mathrm{n}}}{C_{s}}+\frac{\operatorname{cov}\left(w_{\mathrm{n}}, F_{\mathrm{n}}\right)}{\sigma_{w_{n}}^{2}}\right] .
$$

Each term in this expanded equation turns out to be associated with a specific physical control. We now examine each term individually.

\subsection{Term 1: Effect of Nonstationarity}

The first term in (22), $\sigma_{w_{\mathrm{n}}} / \sigma_{w_{\mathrm{n}+1}}$, reflects nonstationarity (seasonality) in the atmospheric forcing. If the statistics of this forcing did not vary with season, then the statistics of soil moisture could not vary with season, and the term $\sigma_{w_{\mathrm{n}}} / \sigma_{w_{\mathrm{n}+1}}$ would be identically 1 . Precipitation and net radiation, however, almost always have strong seasonal cycles, and thus $\sigma_{w_{n}}$ and $\sigma_{w_{n+1}}$ are rarely equal. Depending on the magnitudes of the other terms in (22), the nonstationarity effect can be highly important.

To get an intuitive feel for the control of nonstationarity on soil moisture memory, consider the two extreme examples in Figure 6. For simplicity, these examples focus on precipitation variability alone. In Case 1 , the precipitation variance of month $n$ is assumed to be low, and that of the preceding months is assumed to be high. Reflecting the high precipitation variance in the earlier months is a high soil moisture variance at the beginning of month $n$; the terms $w_{\mathrm{a}, \mathrm{n}}$ and $w_{\mathrm{b}, \mathrm{n}}$ represent two possible - and well separated - values of soil moisture at the beginning of the month. Because the precipitation variance 
in month $n$ is low, the range of possible monthly soil moisture change, $\Delta w$, for month $n$ must also be low, and $w_{\mathrm{a}, \mathrm{n}}$ and $w_{\mathbf{b}, \mathrm{n}}$ will thus evolve to new values that are still distinct from each other. In other words, a high soil moisture anomaly will tend to remain relatively high. The situation outlined in Case 1 is conducive to high soil moisture autocorrelation.

In Case 2, on the other hand, the precipitation variance of month $n$ is assumed to be high, and that of the preceding months is assumed to be low. In this case, the variance of soil moisture at the beginning of month $n$ must be small, and $w_{\mathrm{a}, \mathrm{n}}$ and $w_{\mathrm{b}, \mathrm{n}}$ will necessarily be close together. Then, because the precipitation variance in month $n$ is large, $\Delta w$ can be large, and $w_{\mathrm{a}, \mathrm{n}}$ and $w_{\mathbf{b}, \mathbf{n}}$ can both evolve to either high or low values. In essence, the high precipitation variance swamps out the initial distinction between $w_{\mathbf{a}, \mathrm{n}}$ and $w_{\mathrm{b}, \mathrm{n}}$, so that memory of the distinction is lost. Case 2 is conducive to low soil moisture autocorrelation.

Figure 7 shows the global distribution of the scaling factor $\sigma_{w_{n}} / \sigma_{w_{n+1}}$, as determined from the AGCM's July diagnostics. The factor is large (that is, case 1 applies, leading to increased persistence) across the deserts of northern Africa and central Asia and across southern Africa and Australia. On the other hand, the scaling factor is small (and thus persistence is reduced) in eastern Asia, central Europe, and the equatorial Amazon. The value of $\sigma_{w_{\mathrm{n}}} / \sigma_{w_{\mathrm{n}+1}}$ naturally has an upper limit; when multiplied by the other factor in (22), the product must be less than or equal to one. Note also that if 
$\sigma_{w_{n}} / \sigma_{w_{n+1}}$ is greater than one in one season, it must necessarily be less than one in another season. The results in Figure 7 are specific to July.

\subsection{Term 2: The Evaporation Effect}

The second term in (22), $\frac{c \bar{R}_{\mathrm{n}}}{C_{s}}$, is the "evaporation effect", through which characteristics of the land surface model $\left(c\right.$ and $C_{s}$ ) and the radiative forcing $\left(\bar{R}_{\mathrm{n}}\right)$ combine to reduce soil moisture persistence. The mechanism behind this reduction is illustrated by rewriting (4) as

$$
\frac{E_{\mathrm{ni}}}{C_{s}}=\frac{c R_{\mathrm{ni}}}{C_{s}} w_{\mathrm{ni}}+\frac{d R_{\mathrm{ni}}}{C_{s}}
$$

where $E_{\mathrm{ni}} / C_{s}$ represents the change in the degree of soil moisture saturation attributable to evaporation. The top plot in Figure 8 shows that (23) induces different values of $E_{\mathrm{n}} / C_{s}$ in response to two different soil moistures $w_{\mathrm{j}, \mathrm{n}}$ and $w_{\mathrm{i}, \mathrm{n}}$. The resulting changes in the degree of saturation are thus different, and the final values of $w_{\mathrm{j}}$ and $w_{\mathrm{i}}$ are closer together than they were at the beginning of the month (see bottom plot in figure). Because soil moisture persistence translates into a soil moisture anomaly's ability to retain its distinctiveness from other possible states over time, anything that acts to reduce that distinctiveness - anything that acts to brings distinct states closer together - should reduce the autocorrelation. In fact, (22) implies that on average, the evaporation effect decreases the autocorrelation (before the scaling by $\left.\sigma_{w_{\mathrm{n}}} / \sigma_{w_{\mathrm{n}+1}}\right)$ by $c \bar{R}_{\mathrm{n}} / C_{s}$. This is the restoring influence of evaporation on soil moisture anomalies. 
Figure 9 (top) shows the global distribution of $\frac{c \bar{R}_{\mathrm{n}}}{C_{s}}$ for July. The evaporation effect strongly reduces persistence in dry areas of the continents, with especially large reductions in the western United States. Reasons for the distinction between wet and dry areas in the map are twofold: (1) dry areas typically have less vegetation and accordingly have a lower water holding capacity, $C_{s}$; and (2) in wet areas, the evaporation is controlled more by atmospheric demand than by soil water content, and accordingly, the slope $c$ is smaller there.

\subsection{Term 3: The Runoff Effect}

An analogous interpretation applies to the restoring influence of runoff. The "runoff effect" is represented by the third term in $(22), a \bar{P}_{\mathrm{n}} / C_{s}$. We can rewrite (3) as

$$
\frac{P_{\mathrm{ni}}-Q_{\mathrm{ni}}}{C_{s}}=\frac{P_{\mathrm{ni}}}{C_{s}}(1-b)-\frac{a P_{\mathrm{ni}} w_{\mathrm{ni}}}{C_{s}}
$$

where $\left(P_{\mathrm{ni}}-Q_{\mathrm{ni}}\right) / C_{s}$ represents the increase in the degree of saturation resulting from the infiltration of rainwater. Note that because $a \bar{P}_{\mathrm{n}} / C_{s}$ is positive, a lower (drier) value of $w_{\mathrm{ni}}$ implies a higher value of $\left(P_{\mathrm{ni}}-Q_{\mathrm{ni}}\right) / C_{s}$. In other words, although two different soil moisture states would both increase in response to a rain event, the drier state would increase more, and the two states would be brought closer together, in direct analogy to the reduction in the distinction of states shown in Figure 8. Again, this implies a decrease in persistence. From (22), the average decrease in persistence due to the runoff 
effect amounts to $a \bar{P}_{\mathrm{n}} / C_{s}$.

Figure 9 (middle) shows the geographical variation of $a \bar{P}_{\mathrm{n}} / C_{s}$ for July. The runoff effect reduces soil moisture persistence substantially in Central America, the islands of the west Pacific, parts of the Amazon, and parts of China. It also affects, to a lesser degree, persistence in high latitudes. A comparison of the maps for $c \bar{R}_{\mathrm{n}} / C_{s}$ and $a \bar{P}_{\mathrm{n}} / C_{s}$ reveals that the evaporation and runoff effects essentially act in different regions. The reason is straightforward - whereas the evaporation effect is enhanced in dry regions (for the reasons noted above), the runoff effect is enhanced in wet regions because: (i) $\bar{P}_{\mathrm{n}}$ is higher in wet regions; and (ii) in the Mosaic LSM, the fitted slope $a$ is higher when the average soil moisture is higher, due in part to higher hydraulic conductivity.

Thus, an especially dry region and an especially wet region both tend to have low soil moisture memory, but for entirely different reasons. Neither $a \bar{P}_{\mathrm{n}} / C_{s}$ nor $c \bar{R}_{\mathrm{n}} / C_{s}$ is typically large in regions of intermediate wetness, and thus in these regions, (22) often predicts high soil moisture memory.

\subsection{Term 4: Persistence of Atmospheric Forcing}

The final term in $(22), \operatorname{cov}\left(w_{n}, F_{n}\right) / \sigma_{w_{n}}^{2}$, encompassses the "forcing persistence" effect, which is fairly intuitive. Clearly, if precipitation shows a high temporal correlation - if high precipitation in one month tends to be followed by high precipitation in the next - then soil moisture will also show a high temporal correlation, since soil moisture anomalies largely reflect prior 
precipitation anomalies. In the NSIPP AGCM, as in earlier versions of the model, precipitation persistence is high in many parts of the tropics [Scott et al., 1995; Koster and Suarez, 1995]. These high values are presumably reflected in the tropical soil moisture autocorrelations shown in Figure 3a.

Figure 9 (bottom) shows the geographical distribution of $\operatorname{cov}\left(w_{n}, F_{n}\right) / \sigma_{w_{n}}^{2}$ for July. The positive sign of this term in (22) implies that the forcing persistence effect can compensate for some of the persistence lost through the evaporation and runoff effects. Such compensation is indeed seen, for example, in parts of the western United States, in the Sahel, and the western Pacific islands. Obviously, the value of $\operatorname{cov}\left(w_{\mathrm{n}}, F_{\mathrm{n}}\right) / \sigma_{w_{n}}^{2}$ has an upper limit defined by the other terms in the equation, for the equation as a whole cannot produce an autocorrelation that exceeds one.

\subsection{Relative Impact of Identified Controls}

Through analysis of the maps in Figures 7 and 9 in conjunction with the autocorrelation maps in Figure 3, we can isolate and quantify the physical controls on soil moisture memory at any grid cell. For example, a look at the maps shows that only nonstationarity and the evaporation effect have a significant impact on soil moisture autocorrelation in most of Australia and that this control is strong enough to reduce the autocorrelation there to intermediate values. In the Sahara, on the other hand, none of the controls is particularly important, and the autocorrelation is very high.

Such qualitative evaluation of the controls on a region's soil moisture 
memory is expedited by histograms such as those in Figure 10. Shown for six different grid cells is an indication of how each of the four identified controls affect the 30-day-lagged autocorrelation $\left(\rho_{30}\right)$ of soil moisture. The first three bars in each plot represent the evaporation effect, the runoff effect, and the forcing persistence effect, respectively; their lengths are set equal to $c \bar{R}_{\mathrm{n}} / C_{s}, a \bar{P}_{\mathrm{n}} / C_{s}$, and $\operatorname{cov}\left(w_{\mathrm{n}}, F_{\mathrm{n}}\right) / \sigma_{w_{n}}^{2}$. Both the evaporation and the runoff effects reduce persistence, and thus their bars lie to the left of the vertical line, whereas the bar for the forcing persistence effect, which increases persistence, lies to the right of the line whenever this effect is statistically significant. The net impact of these three effects (i.e., the sum of $c \bar{R}_{\mathrm{n}} / C_{s}$, $a \bar{P}_{\mathrm{n}} / C_{s}$, and $\left.\operatorname{cov}\left(w_{\mathrm{n}}, F_{\mathrm{n}}\right) / \sigma_{w_{n}}^{2}\right)$ is shown as the fourth bar. As seen from (22), one minus this sum is equivalent to the autocorrelation obtained under the assumption of no seasonality in the atmospheric forcing; this autocorrelation ("EST. $\rho$, NO SEASONALITY") is shown as the fifth bar in the histogram. The impact of seasonality (i.e., the nonstationarity effect) is indicated by the difference between this fifth bar and the one just below it ("EST. $\rho$, W/ SEASONALITY"), which represents the autocorrelation computed with (22). The final bar shows, for comparison, the autocorrelation that was actually simulated at the grid cell.

Through analysis of Figure 10, we can now say that soil moisture memory in the eastern United States cell is reduced solely by the seasonality and runoff effects, in contrast to the west-central United States cell, in which memory is 
also influenced by the evaporation effect and by forcing persistence. Forcing persistence is also significant in the equatorial Amazon and the southeast Asia cells. In the equatorial Amazon, this persistence is strongly counteracted by the runoff effect, and seasonality acts to reduce soil moisture memory even further. In southeast Asia, on the other hand, forcing persistence is only weakly counteracted by the evaporation effect, and the resulting soil moisture autocorrelation is high. In southern Africa, the evaporation effect is counteracted by the seasonality effect, which here acts to increase memory; the net result is a high value of $\rho_{30}$. The low memory in eastern China is induced mostly by the runoff effect.

Again, these are just examples; the soil moisture memory simulated at any land grid cell can be similarly explained in terms of the relative strengths of the four identified controls. Establishing these relative strengths is important because, as noted in section 1 , soil moisture memory can potentially contribute to precipitation predictability at seasonal timescales. If precipitation predictions stemming from soil moisture initialization are to be believed, the memory of soil moisture in the model must be correct for the proper reasons - the relative contributions of the different factors in a given region must agree with those inferred from analysis of meteorological and surface hydrological data. Evaluating the underlying controls on soil moisture memory would be especially helpful in the great majority of regions for which the observed soil moisture data is of insufficient duration for a direct evaluation 
of simulated autocorrelation.

\section{Summary and Discussion}

An equation, (22), for the autocorrelation of soil moisture in an AGCM was derived from water budget considerations and from two simple, fitted functions that relate evaporation and runoff to soil moisture content. Figures 3 and 4 show that the equation successfully reproduces the autocorrelations generated by the modeling system of the NASA Seasonal-to-Interannual Prediction Project (NSIPP). The equation should, in fact, be applicable to any AGCM system.

According to the equation, the autocorrelation of soil moisture - soil moisture "memory" - is mainly controlled by four distinct factors: (i) nonstationarity in the statistics of the forcing, as induced by seasonality, (ii) reduction in anomaly differences through the functional dependence of evaporation on soil moisture (through the slope $c$ ), (iii) reduction in anomaly differences through the functional dependence of runoff on soil moisture (through the slope $a$ ), and (iv) temporal memory in the precipitation and radiation forcing fields, as perhaps induced by land-atmosphere feedback. Thus, soil moisture memory in an AGCM is controlled by a combination of climate properties (through all four factors), land surface model characteristics (through the second and third factors) and land-atmosphere interaction (through the fourth factor). The relative importance of the four controls is roughly indicated by 
the maps in Figures 7 and 9. Through analysis of these maps and associated histograms (e.g., those in Figure 10), one can explain the simulated value of soil moisture autocorrelation at any grid cell - one can describe the extent to which each physical control increases or decreases the memory.

Again, given the dearth of multi-decadal global soil moisture data, the validation of these four controls in an AGCM simulation should aid in the evaluation of simulated soil moisture memory itself. This should in turn contribute to the evaluation of seasonal precipitation predictions that rely on soil moisture initialization and subsequent soil moisture memory. The work presented herein complements the analysis of Koster et al. [2000], who used ensembles of lengthy simulations to examine the sensitivity of rainfall to prescribed surface conditions. Koster et al. [2000] essentially addressed the following question: if soil moisture can be predicted perfectly, to what extent does that improve the prediction of precipitation - i.e., to what extent are precipitation anomalies guided by soil moisture anomalies? The present paper begins to address the critical second part of the problem: to what extent can soil moisture anomalies be predicted in the first place? Both questions must be addressed if we are to assess the contributions of land surface initialization to the seasonal prediction of precipitation.

An interesting application of the framework described in this paper would be the determination of "seasonal barriers" to soil moisture prediction. The factors that determine soil moisture memory do vary seasonally, and as a 
result, soil moisture persistence across particular months may be sharply reduced relative to other months. Identifying these months is critical, since they help define the limits of predictability in the modeling system. Seasonal variations in soil moisture persistence may result, for example, from seasonal variation in the forcing statistics - the two cases outlined in Figure 6 suggest that a region with marked seasonality in precipitation variance should experience some months with enhanced persistence and some months with diminished persistence. Seasonal variations in persistence could also stem from seasonal changes in the overlying atmospheric conditions, since some conditions may be more conducive than others to land-atmosphere feedback, and from seasonal variations in the effective slopes of the evaporation and runoff functions.

An additional source of seasonal variation is more subtle but is worth mentioning here. One can imagine a situation in which the rainfall in a specific month, say July, is always very large, so that soil moistures in July are typically fully saturated (or at some model-specific maximum value). For this situation, knowing what the soil moisture is at the beginning of June does not translate into skill in predicting August soil moisture - all memory is lost in July, when all states collapse into the same very wet state. In the context of the framework described in this paper, this low memory reflects an overwhelming contribution from the runoff effect. In essence, the term $a \bar{P}_{\mathrm{n}} / C_{s}$ is maximized during July to produce a $\rho$ of 0 . 
By the way, the autocorrelation analysis described herein is not inconsistent with that of Delworth and Manabe [1988] (see section 1). In fact, the autocorrelation equation, (22), reduces exactly to their implied form under four assumptions, namely: (i) a lack of seasonality in the atmospheric forcing, (ii) a lack of persistence in the forcing, (iii) the neglect of runoff variation with soil moisture, and (iv) the equivalence of potential evaporation and net radiation. Given the fact that these assumptions are often not justified, (22) can be considered the more complete equation. For most AGCMs, the first assumption in particular is not justified, and for most land surface models, the third is also inappropriate [see, e.g., Koster and Milly, 1997]. The fourth assumption is somewhat dangerous. Equation (22) could not be derived if potential evaporation replaced net radiation in (4); because potential evaporation is strongly correlated with soil moisture, the "higher order" terms neglected in deriving (9) would no longer be negligible. The proper application of (22) to results from a "bucket model" simulation would require the use of net radiation values rather than potential evaporation rates, despite the bucket model's explicit use of the latter.

Finally, we note that by focusing our analysis on boreal summer, the analysis above has ignored some important cold season effects. Significant memory, for example, is associated with the build-up and maintenance of snowpack. Also, when soil moisture freezes in late fall, the associated anomaly is retained in the soil until the soil thaws in the spring. A complete treatment 
of land surface memory should take these additional effects into account.

Acknowledgments. This work was supported by funding from the Earth Science Enterprise of NASA Headquarters through the EOS-Interdisciplinary Science Program and the NASA Seasonal-to-Interannual Prediction Project (NSIPP). All computational resources were provided by the NASA Center for Computational Sciences (NCCS). Lori Tyahla helped with the data processing. 


\section{References}

Bacmeister, J., P. J. Pegion, S. D. Schubert, and M. J. Suarez, Atlas of seasonal means simulated by the NSIPP 1 atmospheric GCM, NASA Tech. Memo. 2000-104606, Vol. 17, 2000.

Delworth, T.L., and S. Manabe, The influence of potential evaporation on the variabilities of simulated soil wetness and climate, J. Clim., 1, 523-547, 1988.

Entin, J. K, A. Robock, K. Y. Vinnikov, S. E. Hollinger, S. Liu, and A. Namkhai, Temporal and spatial scales of observed soil moisture variations in the extratropics, J. Geophys. Res., 105, 11865-11877, 2000.

Georgakakos, K. P., D.-H. Bae, and D. R. Cayan, Hydroclimatology of continental watersheds, 1, Temporal analyses, Wat. Resour.. Res., 31, 655-675, 1995.

Huang, J., H. M. van den Dool, and K. P. Georgakakos, Analysis of modelcalculated soil moisture over the United States (1931-1993) and applications to long-range temperature forecasts, J. Climate, 9, 1350-1362, 1996.

Koster, R. and P. C. D. Milly, The interplay between transpiration and runoff formulations in land surface schemes used with atmospheric models, $J$. Climate, 10, 1578-1591, 1997. 
Koster, R. D. and M. J. Suarez, The influence of land surface moisture retention on precipitation statistics, J. Climate, 9, 2551-2567, 1996a.

Koster, R. and M. Suarez, Energy and Water Balance Calculations in the Mosaic LSM, NASA Tech. Memo. 104606, Vol. 9, 1996b.

Koster, R. D. and M. J. Suarez, The relative contributions of land and ocean processes to precipitation variability, J. Geophys. Res., 100, 13775$13790,1995$.

Koster, R. D. and M. J. Suarez, Modeling the land surface boundary in climate models as a composite of independent vegetation stands, J. Geophys. Res., 97, 2697-2715, 1992.

Koster, R. D., M. J. Suarez, and M. Heiser, Variance and predictability of precipitation at seasonal-to-interannual timescales, J. Hydrometeorology, $1,26-46,2000$.

Kumar, A. and M. P. Hoerling, Prospects and limitations of seasonal atmospheric GCM predictions, Bull. Amer. Met. Soc., 76, 335-345, 1995.

Liu, Y. and R. Avissar, A study of persistence in the land-atmosphere system using a general circulation model and observations, J. Climate, 12, 21392153, 1999a.

Liu, Y. and R. Avissar, A study of persistence in the land-atmosphere system with a fourth-order analytical model, J. Climate, 12, 2154-2168, 1999b. 
Manabe, S., Climate and the ocean circulation, I, The atmospheric circulation and the hydrology of the Earth's surface, Mon. Weather Rev., 97, 739-774, 1969.

Robock, A., K. Y. Vinnikov, G. Srinivasan, J. K. Entin, S. E. Hollinger, N. A. Speranskaya, S. Liu, and A. Namkhai, The global soil moisture data bank, Bull. Am. Met. Soc., 81, 1281-1299, 2000.

Rodriguez-Iturbe, I., D. Entekhabi, and R.L. Bras, Nonlinear dynamics of soil moisture at climate scales, 1, stochastic analysis, Water Resources Research, 27, 1899-1906, 1991.

Scott, R., R. D. Koster, D. Entekhabi, and M. J. Suarez, Effect of a canopy interception reservoir on hydrological persistence in a general circulation model, J. Climate, 8, 1917-1922, 1995.

Shukla, J., 1998: Predictability in the midst of chaos: A scientific basis for climate forecasting. Science, 282, 728-731.

Trenberth, K. E., G. W. Branstator, D. Karoly, A. Kumar, N. C. Lau, and C. Ropelewski, 1998: Progress during TOGA in understanding and modeling global teleconnections associated with tropical sea surface temperatures. J. Geophys. Res., 103, 14291-14324.

Vinnikov, K. Y., A. Robock, N. A. Speranskaya, and A. Schlosser, Scales of temporal and spatial variability of midlatitude soil moisture, J. Geophys. 
Res., 101, 7163-7174., 1996

Vinnikov, K. Y. and I. B. Yeserkepova, Soil moisture, empirical data and model results, J. Climate, 4, 66-79, 1991. 


\section{Figure Captions}

Fig. 1 Effective column water holding capacities $(\mathrm{mm})$ at the scale of the grid cell, as derived from the individual tile values used by the Mosaic model.

Fig. 2 Simulated July evaporation ratio $(E / R)$ and runoff ratio $(Q / P)$ versus root zone soil moisture at $4 \mathrm{GCM}$ grid cells. Each point represents one simulation month. a. Northern Amazon. b. Eastern U.S. c. Central U.S. d. Western U.S.

Fig. 3 Top: Map of simulated 30-day lagged autocorrelation of root zone soil moisture, $\rho_{30}$. Middle: Corresponding map of $\rho_{30}$ as estimated with (18). Bottom: Differences: estimated - simulated autocorrelations.

Fig. 4 Scatter plot showing, for each ice-free and ocean-free GCM grid cell, the degree to which the simulated 30-day lagged autocorrelation of soil moisture agrees with the value estimated with (18).

Fig. 5 Same as Figure 4, except considering only points for which the water holding capacity in the root zone exceeds $200 \mathrm{~mm}$.

Fig. 6 Illustration of how nonstationarity in precipitation statistics can affect soil moisture memory. See text for details.

Fig. 7 Global distribution of $\sigma_{w_{n}} / \sigma_{w_{n+1}}$, the scaling factor associated with seasonality (nonstationarity) in the atmospheric forcing. 
Fig. 8 Illustration of how the terms in (22) can affect soil moisture memory. See text for details.

Fig. 9 Global fields of $c \bar{R}_{\mathrm{n}} / C_{s}$ (top), $a \bar{P}_{\mathrm{n}} / C_{s}$ (middle), and $\operatorname{cov}\left(w_{\mathrm{n}}, F_{\mathrm{n}}\right) / \sigma_{w_{\mathrm{n}}}^{2}$ (bottom).

Fig. 10 Histograms showing the impact of four factors (the evaporation effect, the runoff effect, forcing persistence, and seasonality) on the 30day-lagged autocorrelation $\left(\rho_{30}\right)$ of soil moisture. For the top three bars in each plot, the $\mathrm{x}$-axis is the change in $\rho_{30}$ resulting from the indicated factor; a positive value implies that the factor acts to increase $\rho_{30}$, whereas a negative value implies that it acts to decrease $\rho_{30}$. The net impact of these three factors is shown with the fourth bar. The final three bars show three values for $\rho_{30}$ : that estimated with (22), but assuming no seasonality (equivalent to one minus the previous sum); that estimated with the full (22); and that actually simulated by the GCM. The difference between the first two of these $\rho_{30}$ values indicates the impact of the seasonality effect. 


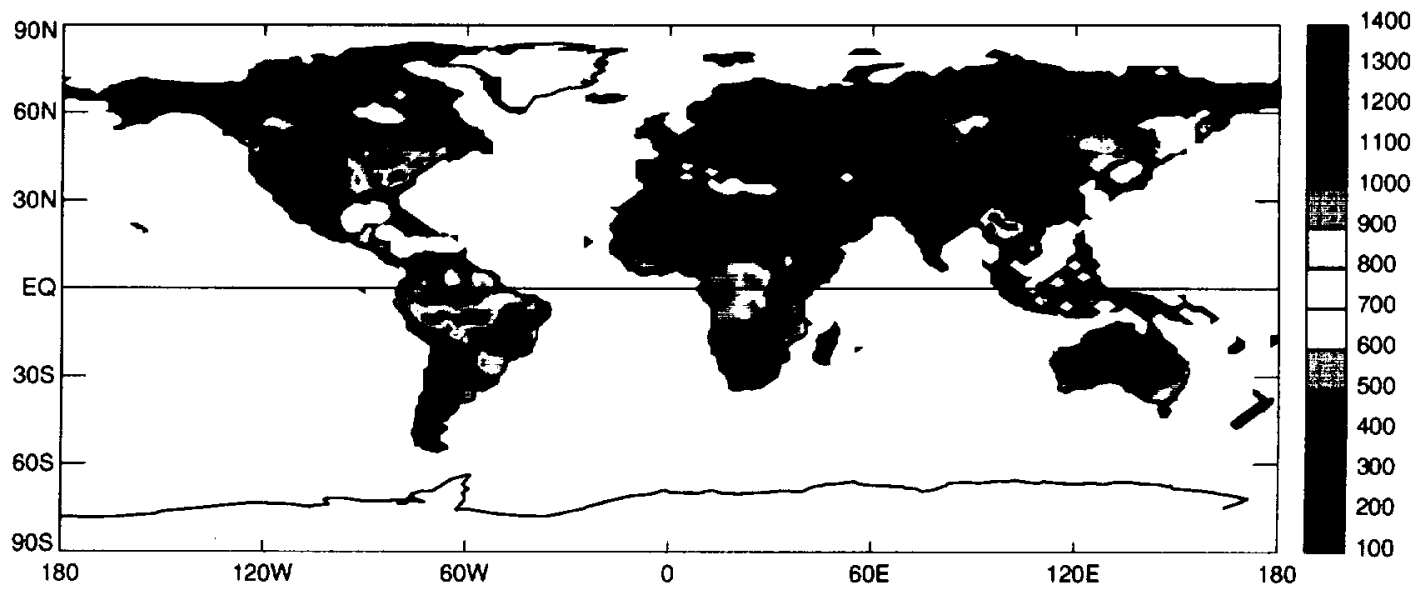

Figure 1: Effective column water holding capacities (mm) at the scale of the grid cell, as derived from the individual tile values used by the Mosaic model. 
a. TROPICAL LAND $(65 \mathrm{~W}, 8 \mathrm{~N})$
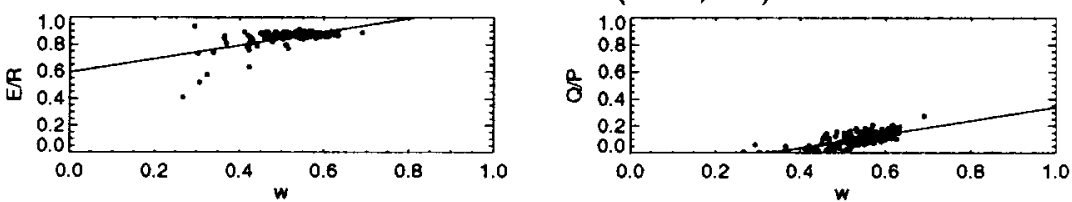

b. EASTERN U.S. (85W, $36 \mathrm{~N})$
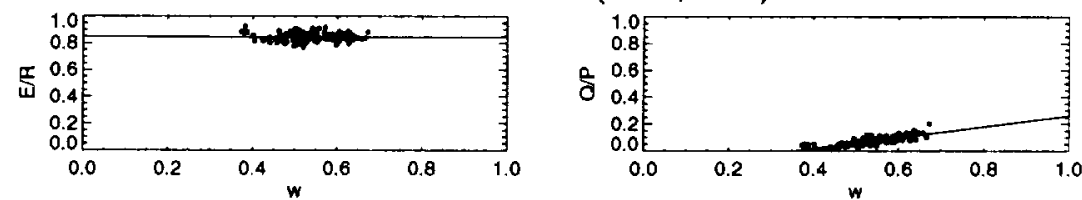

c. CENTRAL U.S. $(97.5 \mathrm{~W}, 36 \mathrm{~N})$
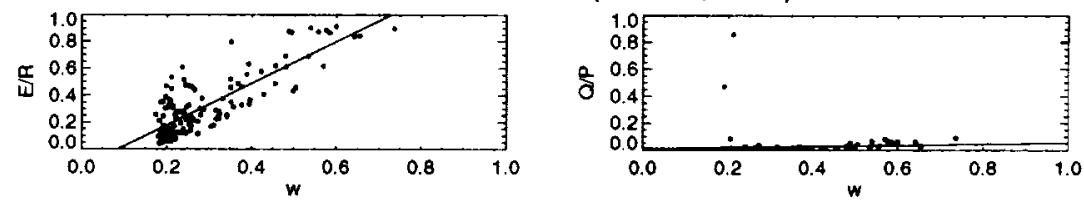

d. WESTERN U.S. (110W, 36N)
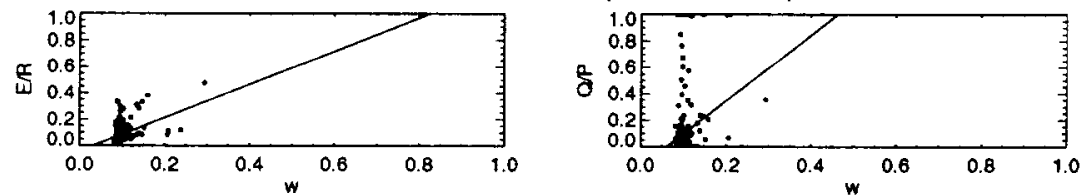

Figure 2: Simulated July evaporation ratio $(E / R)$ and runoff ratio $(Q / P)$ versus root zone soil moisture at $4 \mathrm{AGCM}$ grid cells. Each point represents one simulation month. a. Northern Amazon. b. Eastern U.S. c. Central U.S. d. Western U.S. 

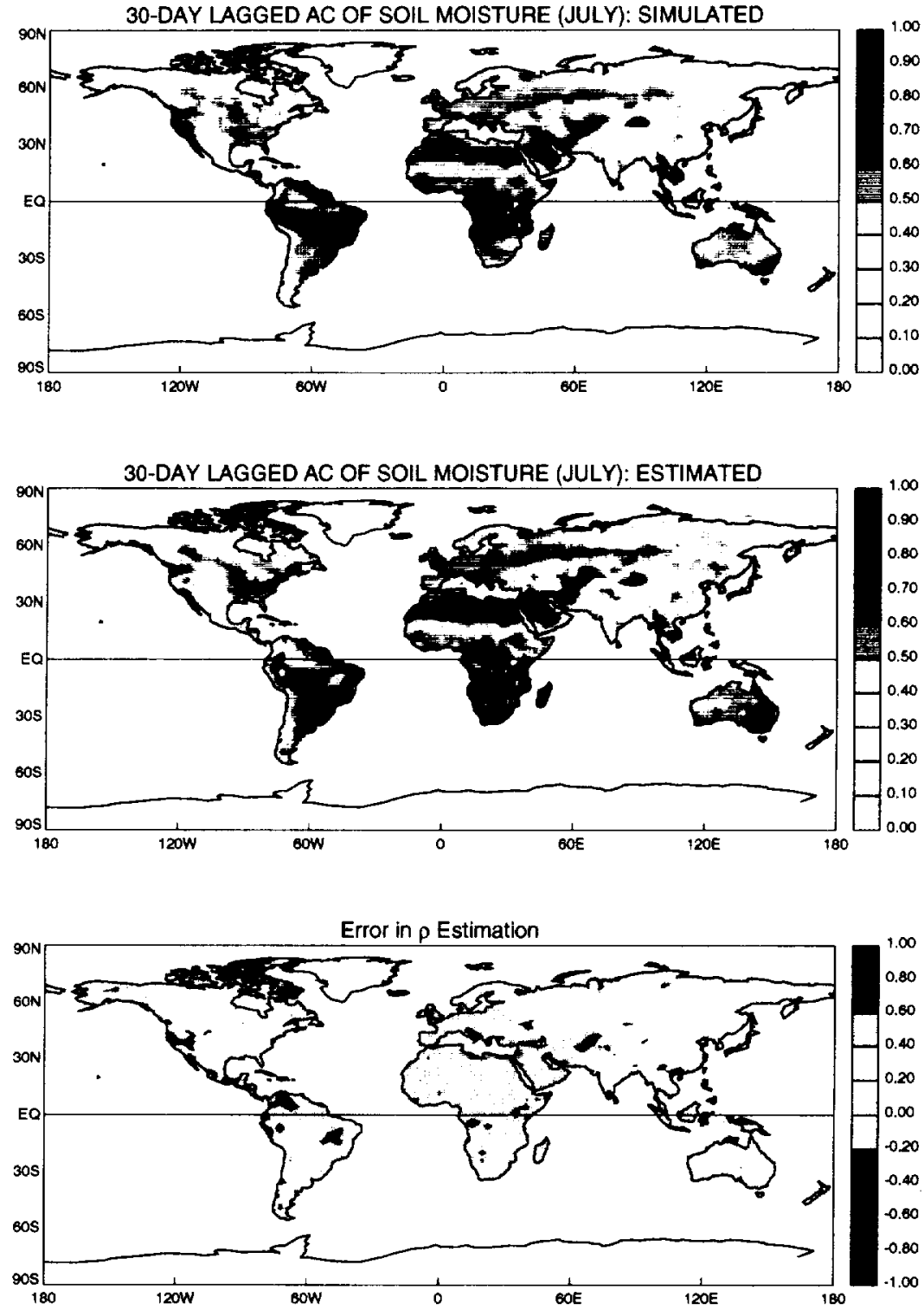

Figure 3: Top: Map of simulated 30-day lagged autocorrelation of root zone soil moisture, $\rho_{30}$. Middle: Corresponding map of $\rho_{30}$ as estimated with (18). Bottom: Differences: estimated - simulated autocorrelations. 


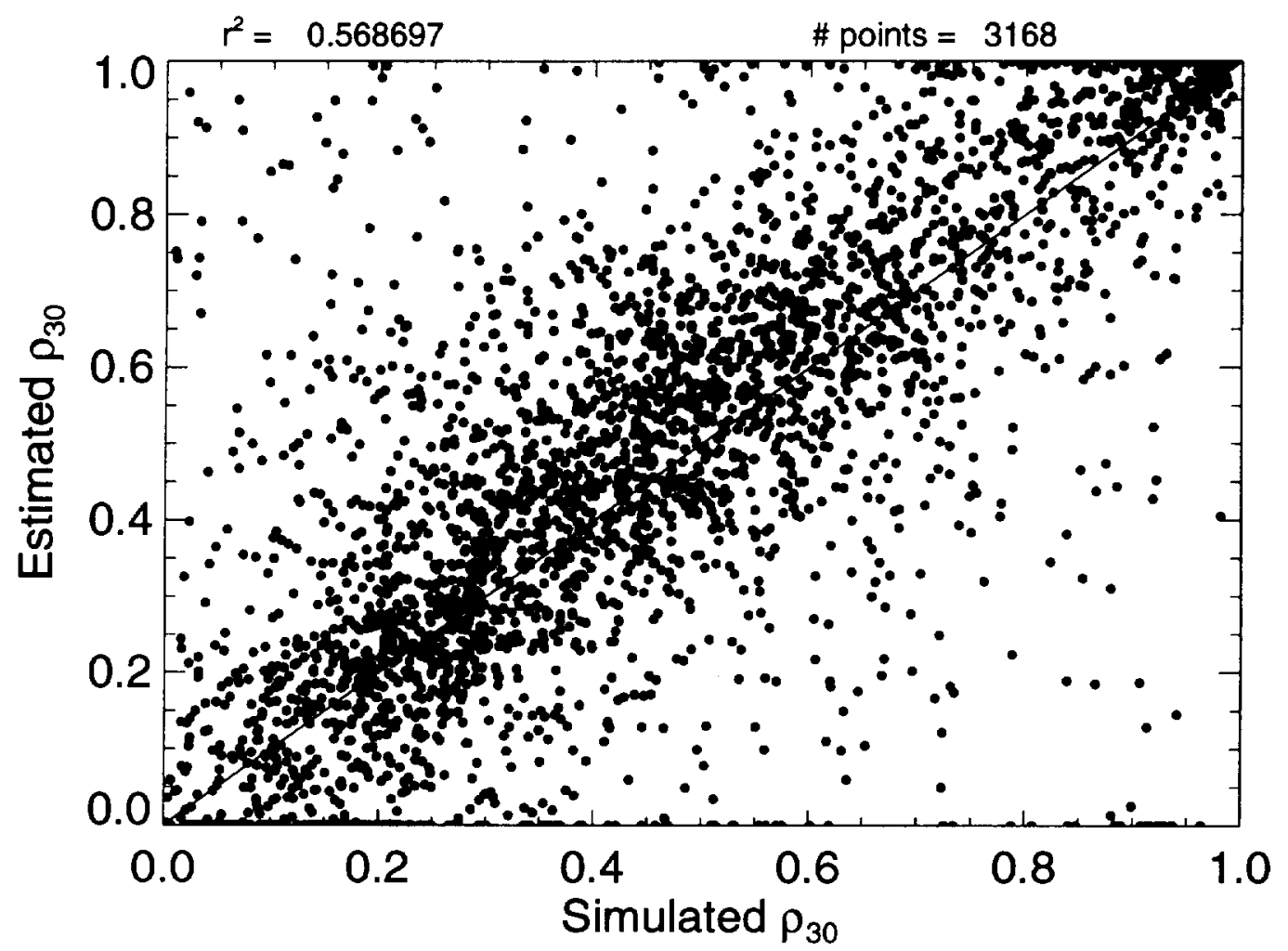

Figure 4: Scatter plot showing, for each ice-free and ocean-free AGCM grid cell, the degree to which the simulated 30-day lagged autocorrelation of soil moisture agrees with the value estimated with (18). 


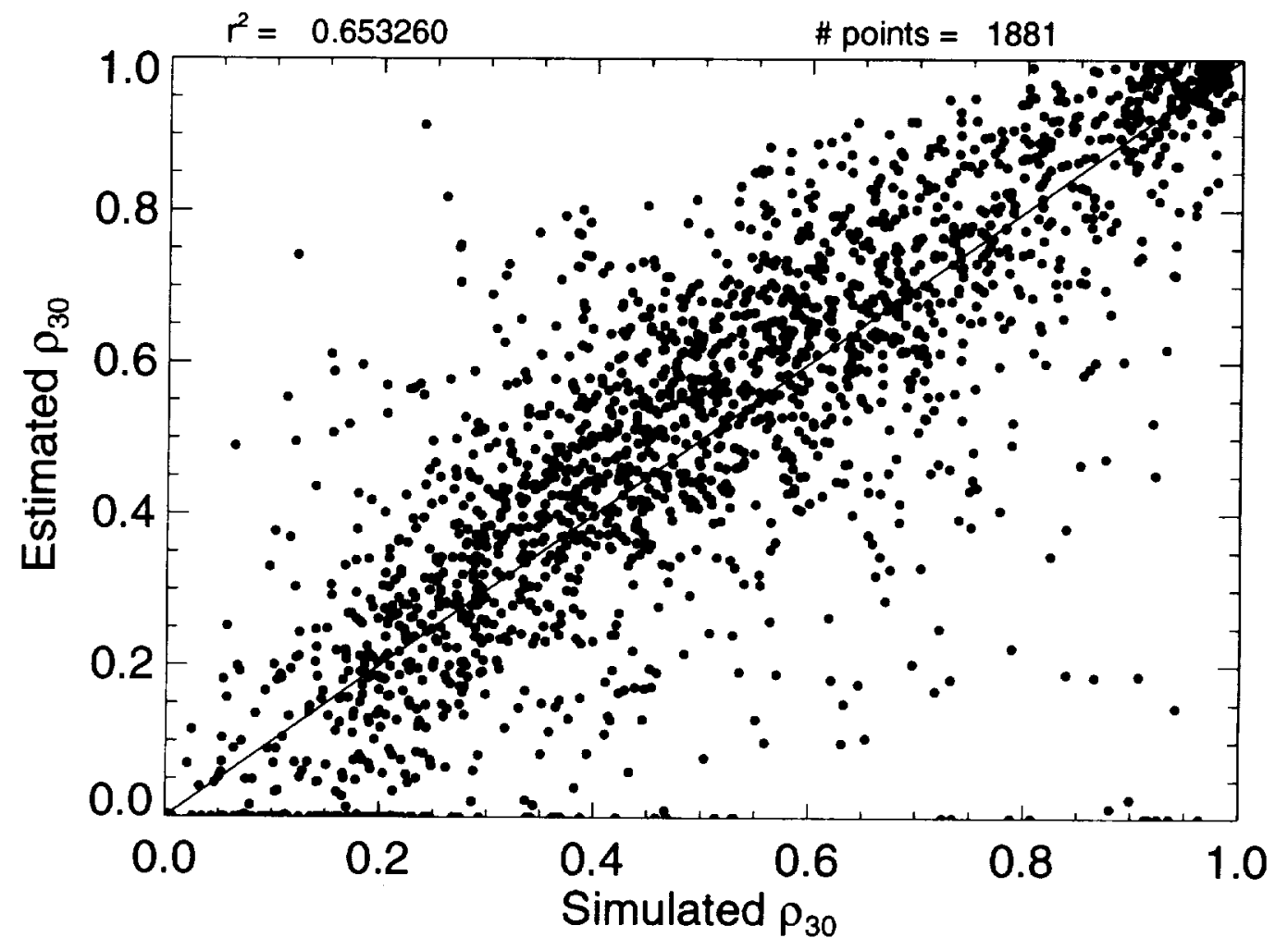

Figure 5: Same as Figure 4, except considering only points for which the water holding capacity in the root zone exceeds $200 \mathrm{~mm}$. 


$$
\begin{aligned}
& \text { Case 1: A month of low } \\
& \sigma_{\mathrm{p}}^{2} \text { follows several months } \\
& \text { of high } \sigma_{\mathrm{p}}^{2}
\end{aligned}
$$

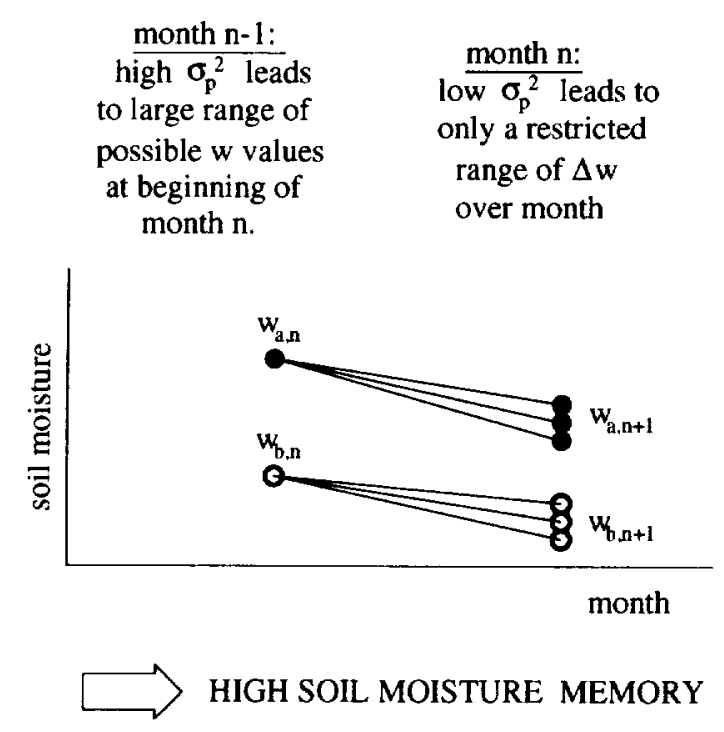

$$
\begin{aligned}
& \text { Case 2: A month of high } \\
& \sigma_{\mathrm{p}}^{2} \text { follows several months } \\
& \text { of low } \sigma_{\mathrm{p}}^{2}
\end{aligned}
$$

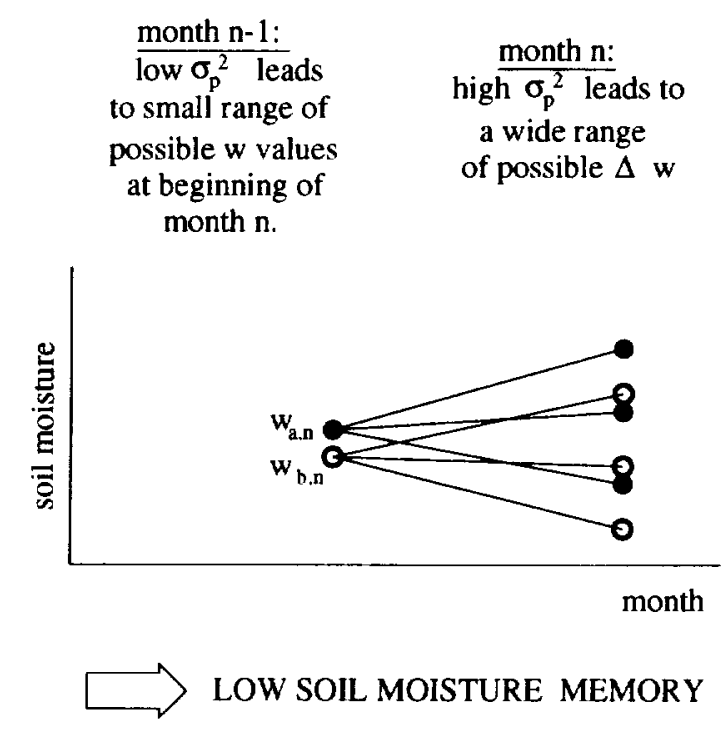

Figure 6: Illustration of how nonstationarity in precipitation statistics can affect soil moisture memory. See text for details. 


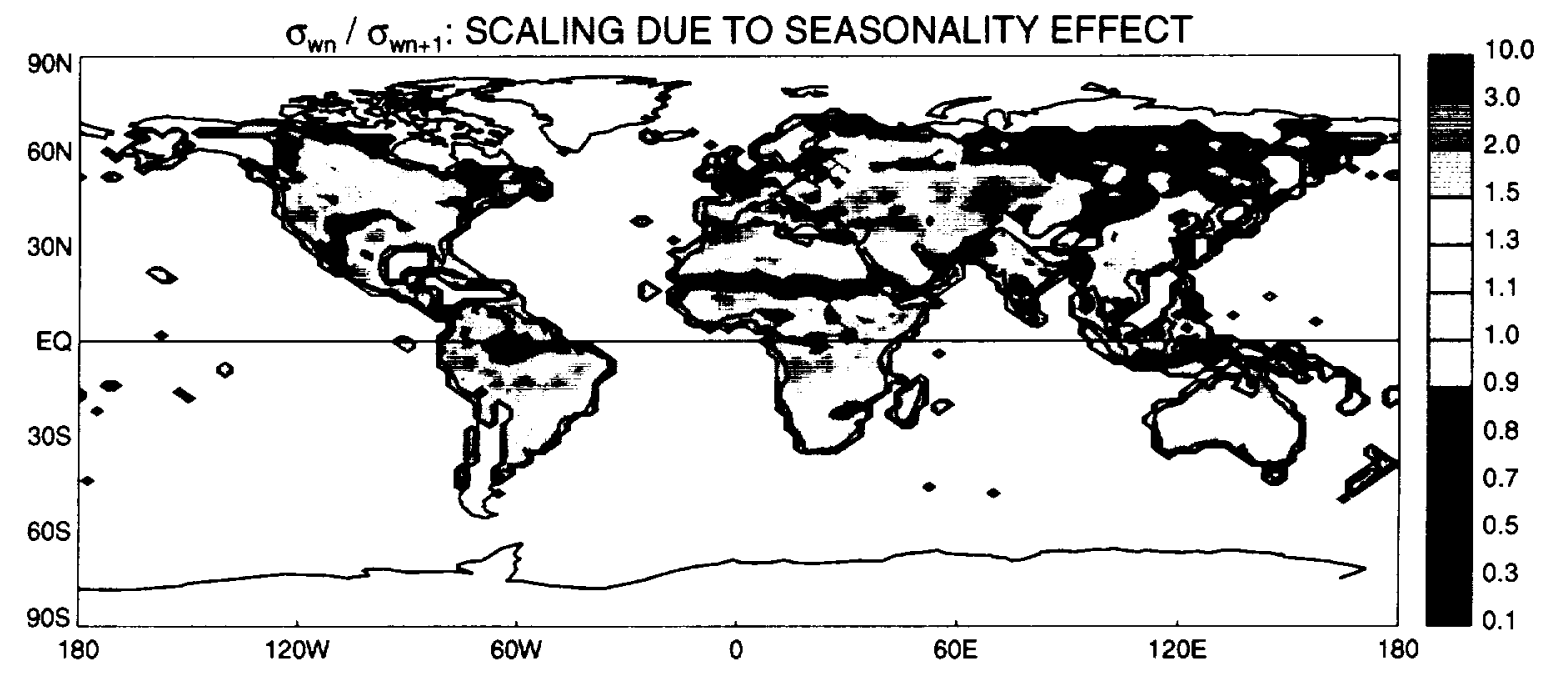

Figure 7: Global distribution of $\sigma_{w_{n}} / \sigma_{w_{n+1}}$, the scaling factor associated with seasonality (nonstationarity) in the atmospheric forcing. 

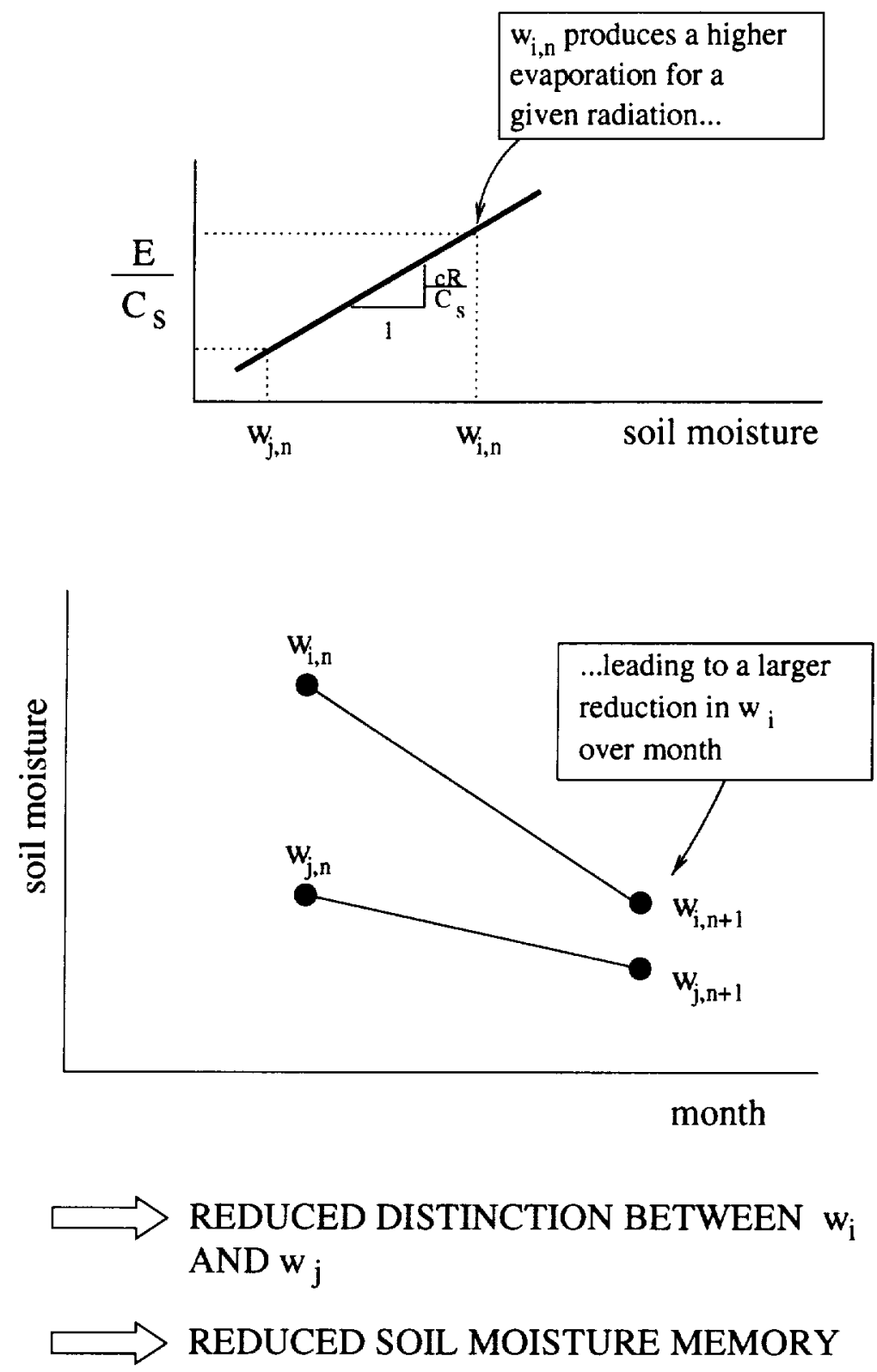

Figure 8: Illustration of how the terms in (22) can affect soil moisture memory. See text for details. 

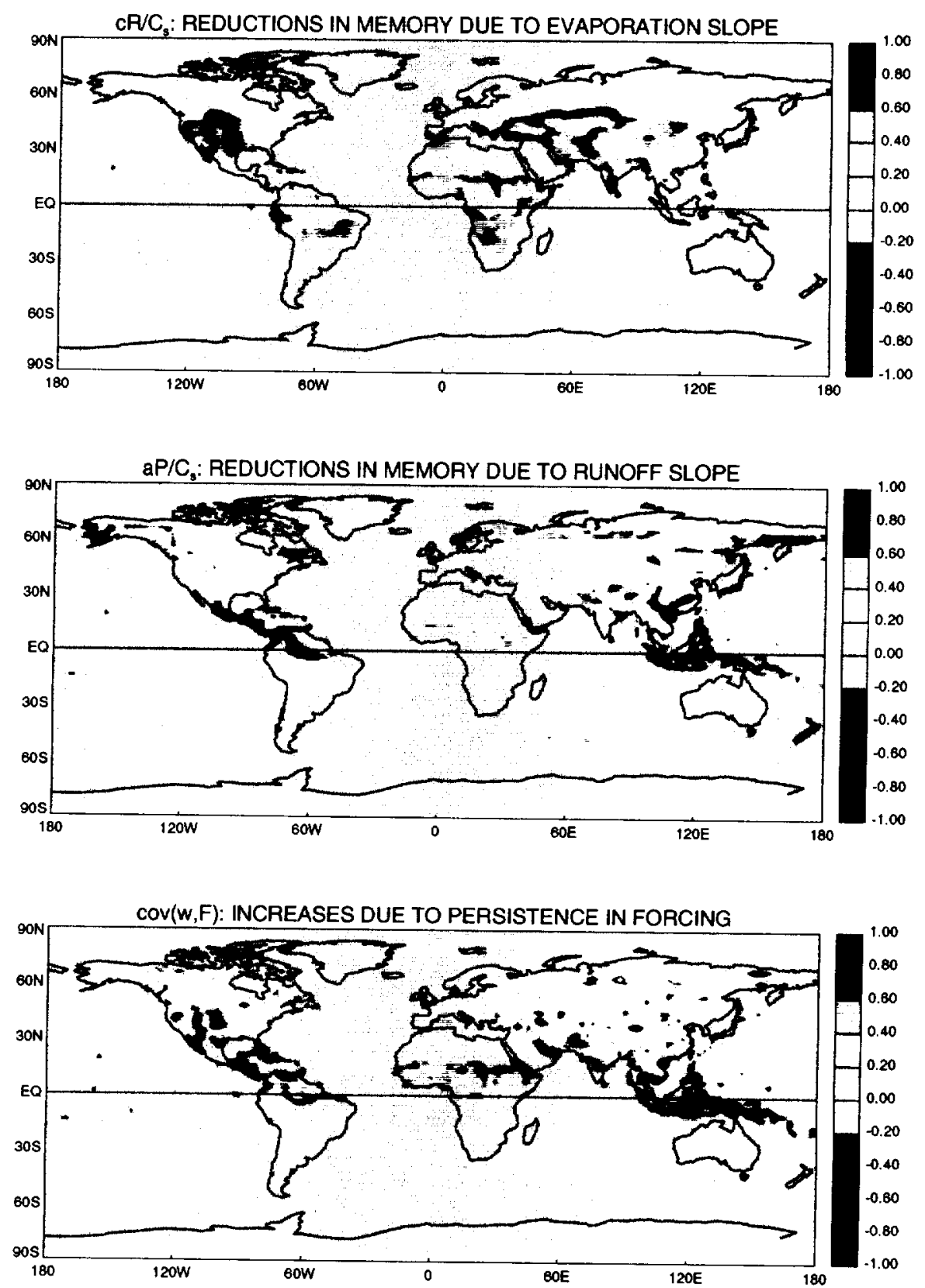

Figure 9: Global fields of $c \bar{R}_{\mathrm{n}} / C_{s}$ (top), $a \bar{P}_{\mathrm{n}} / C_{s} \quad$ (middle), and $\operatorname{cov}\left(w_{\mathrm{n}}, F_{\mathrm{n}}\right) / \sigma_{w_{n}}^{2}$ (bottom). 


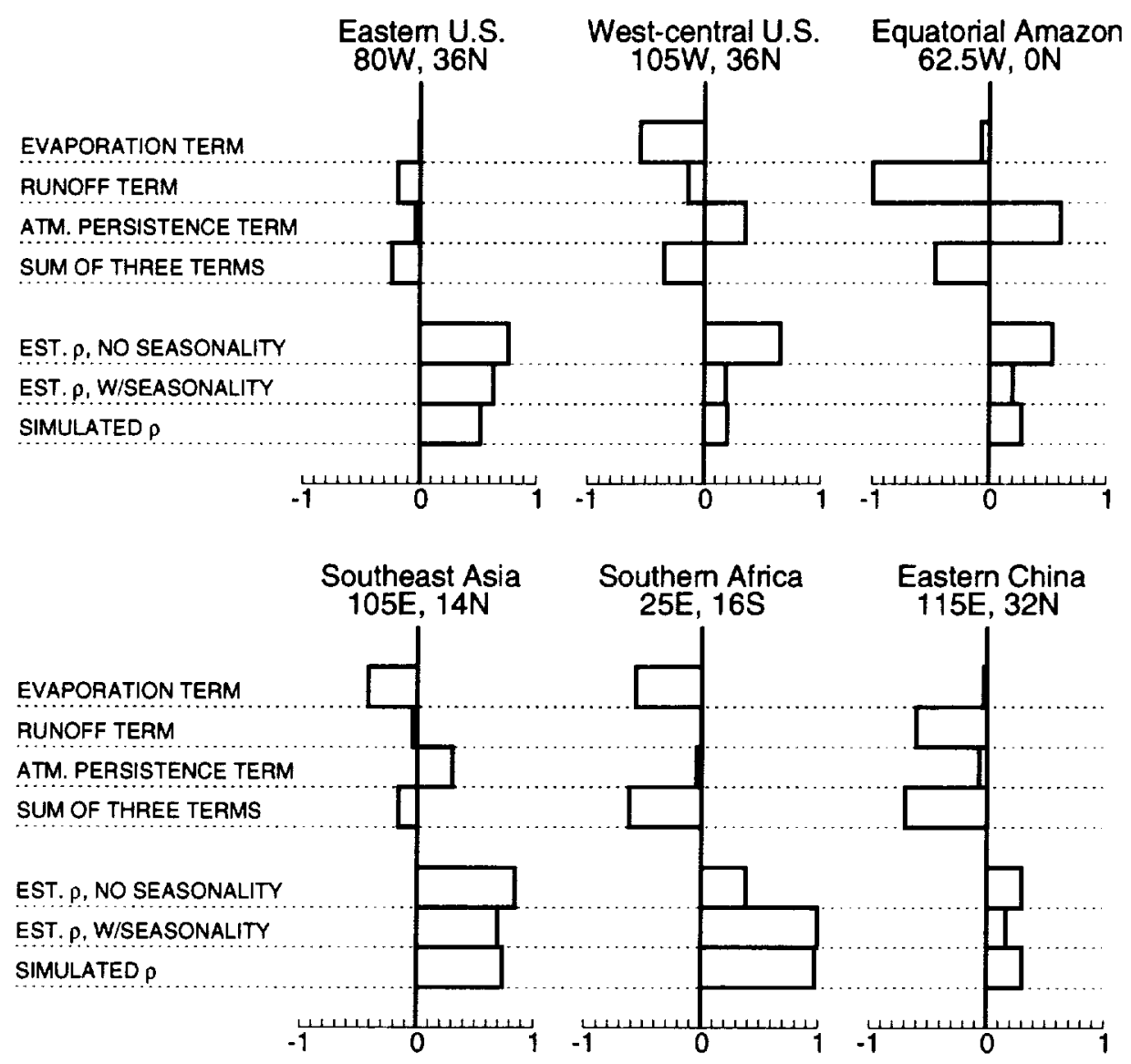

Figure 10: Histograms showing the impact of four factors (the evaporation effect, the runoff effect, forcing persistence, and seasonality) on the 30-daylagged autocorrelation $\left(\rho_{30}\right)$ of soil moisture. For the top three bars in each plot, the $\mathrm{x}$-axis is the change in $\rho_{30}$ resulting from the indicated factor; a positive value implies that the factor acts to increase $\rho_{30}$, whereas a negative value implies that it acts to decrease $\rho_{30}$. The net impact of these three factors is shown with the fourth bar. The final three bars show three values for $\rho_{30}$ : that estimated with (22), but assuming no seasonality (equivalent to one minus the previous sum); that estimated with the full (22); and that actually simulated by the AGCM. The difference between the first two of these $\rho_{30}$ values indicates the impact of the seasonality effect. 